\title{
Interaction of Asialo von Willebrand Factor with Glycoprotein Ib Induces Fibrinogen Binding to the Glycoprotein IIb/llla Complex and Mediates Platelet Aggregation
}

Luigi De Marco, Antonio Girolami, Susan Russell, and Zaverio M. Ruggeri

Centro Immunotrasfusionale, Ospedale Civile, Pordenone, Italy; Istituto di Semeiotica Medica, Università degli Studi, Padova, Italy; and Departments of Basic and Clinical Research and of Immunology, Scripps Clinic and Research Foundation, La Jolla, California 92037

\section{Abstract}

von Willebrand factor (vWF) is necessary for the initial attachment of platelets to exposed subendothelium, particularly under flow conditions like those prevailing in the microcirculation. Little is known about its possible participation in subsequent events leading to formation of platelet thrombi at sites of vascular injury. We addressed this question by studying the mechanisms by which desialylated VWF induces platelet aggregation in the absence of any other stimulus. Asialo vWF, unlike the native molecule, does not require ristocetin to interact with platelets. Agglutination induced by ristocetin is largely independent of active platelet metabolism and only partially reflects physiological events. We have shown here that binding of asialo vWF to platelets was accompanied by release of dense granule content and subsequent ADP-dependent fibrinogen binding to receptors on the glycoprotein (GP) IIb/IIIa complex. The initial interaction of asialo vWF with platelets was mediated by GPIb, as shown by blocking obtained with monoclonal antibody. Inhibition of this initial interaction completely abolished platelet aggregation induced by asialo vWF. The same effect was obtained with a monoclonal antiGPIIb/IIIa antibody. This, however, did not block asialo vWF binding to platelets, but rather inhibited subsequent fibrinogen binding induced by asialo vWF. Therefore, the latter process was also essential for platelet aggregation under the conditions described. At saturation, asialo vWF induced binding of between 3.2 and $27.7 \times 10^{3}$ fibrinogen molecules/platelet, with an apparent dissociation constant between 0.28 and $1.18 \times 10^{-6}$ M. This study shows that asialo, and possibly native, vWF acts as a platelet agonist after its binding to GPIb and induces aggregation through a pathway dependent on GPIb/IIIarelated receptors.

\section{Introduction}

Normal platelet function requires the participation of specific plasma proteins. Among these, von Willebrand factor $(\mathrm{vWF})^{1}$

Presented in part at the XXV Meeting of the American Society of Hematology, San Francisco, 3-6 December 1983, and published in abstract form in 1983. Blood. 62(Suppl. 1):254. This is publication No. 3278 IMM of Scripps Clinic and Research Foundation. Address correspondence to Dr. Ruggeri, Scripps Clinic and Research Foundation, BCR8, 10666 North Torrey Pines Rd., La Jolla, CA 92037.

Received for publication 14 September 1984 and in revised form 12 December 1984.

J. Clin. Invest.

(c) The American Society for Clinical Investigation, Inc.

0021-9738/85/04/1198/06 \$1.00

Volume 75, April 1985, 1198-1203 mediates platelet adhesion to exposed subendothelium (1), and fibrinogen is necessary for platelet-platelet interaction (aggregation) (2). These proteins have been shown to bind to specific sites on the platelet membrane, but only in the presence of appropriate agonists. The antibiotic ristocetin induces binding of vWF to the platelet membrane glycoprotein (GP) $\mathrm{Ib}(3,4)$. ADP, thrombin, and epinephrine, on the other hand, stimulate the binding of fibrinogen to the GP IIb/IIIa complex $(2,5-10)$.

Ristocetin-induced platelet agglutination is independent of divalent cations and platelet metabolism (3) and, in this respect, does not reflect the processes that, in vivo, lead to the formation of a platelet thrombus. Recently, it has been shown that desialylated human vWF aggregates platelets directly when added to platelet-rich plasma (11-13). Since native vWF does not interact with unstimulated platelets, we used asialo vWF to explore the mechanisms by which platelets are activated in the absence of ristocetin or any other platelet agonist. In contrast to ristocetin-induced agglutination, aggregation induced by asialo vWF requires divalent cations and one or more plasma cofactors (13).

In this report we show that one such cofactor is fibrinogen. In addition we show that, as a consequence of asialo vWF binding to GPIb, specific fibrinogen receptors related to the GPIIb/IIIa complex become exposed on platelets. Thus, vWF not only promotes platelet adhesion to the subendothelium, but also induces fibrinogen-dependent platelet aggregation. Therefore, the role of vWF in initiating the hemostatic mechanism may be more complex than previously suspected.

\section{Methods}

Purification of $v W F$ and fibrinogen. The method used for the purification of vWF from plasma was recently published in detail (13-15). The purified vWF used in these experiments was in $0.02 \mathrm{M}$ Tris, $0.15 \mathrm{M}$

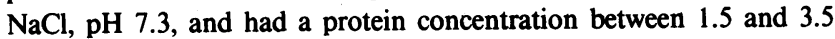
$\mathrm{mg} / \mathrm{ml}$. Each preparation was tested for ristocetin cofactor activity, using a method previously described (16), and found to contain between 107 and $142 \mathrm{U} / \mathrm{mg}$. The multimeric composition was assessed in all samples using agarose electrophoresis in the presence of sodium dodecyl sulfate (SDS) (17). Multimers of all sizes were present and the complex multimeric structure was similar to that of plasma vWF (17). Purity was assessed as described previously (4).

Blood for the purification of fibrinogen was collected into onetenth final volume of citrate-phosphate-dextrose anticoagulant, containing $1 \mathrm{M} \epsilon$-aminocaproic acid. The purification scheme used was

1. Abbreviations used in this paper: FSBA, 5'-p-fluorosulfonylbenzoyladenosine; GP, glycoprotein; GP Ib, GP IIb, and GP IIIa, glycoproteins Ib, IIb, and IIIa; $K_{d}$, dissociation constant; vWF, von Willebrand factor. 
that described by Kazal et al. (18), with few modifications (13). The purified fibrinogen was finally concentrated to $11-34 \mathrm{mg} / \mathrm{ml}$ and dialyzed against $0.02 \mathrm{M}$ Tris, $0.15 \mathrm{M} \mathrm{NaCl}, \mathrm{pH} 7.3$. Clottability was $>93 \%$. SDS-polyacrylamide gel electrophoresis $(10 \%$ acrylamide with $5 \%$ cross-linking) under reducing conditions (19) showed the typical $\mathrm{A} \alpha, \mathrm{B} \beta$, and $\gamma$ chains.

Desialylation of $v W F$. The purified $v W F$ was treated with proteasefree neuraminidase from Vibrio cholerae (Calbiochem-Behring Corp., La Jolla, CA) as previously described (13). Desialylated vWF was freed of active enzyme and released sialic acid as reported $(13,20)$. The sialic acid content was measured by the method of Warren (21). Asialo vWF was concentrated to $0.74-1.5 \mathrm{mg} / \mathrm{ml}$, and then extensively dialyzed against $0.02 \mathrm{M}$ Tris, $0.15 \mathrm{M} \mathrm{NaCl}, \mathrm{pH}$ 7.3. In six different preparations, the sialic acid content after treatment with neuraminidase was (mean $\pm \mathrm{SD}$ ) $5.2 \pm 1.7 \mathrm{nmol} / \mathrm{mg}$ protein, as opposed to $132.4 \pm 16.7$ $\mathrm{nmol} / \mathrm{mg}$ protein in the corresponding native $\mathrm{vWF}$. This represented a removal of $>95 \%$. The multimeric structure and ristocetin cofactor activity of asialo vWF were identical to those of native vWF (20).

Radioiodination of proteins. This was performed with ${ }^{125} \mathrm{I}$ by the method of Fraker and Speck (22) to $0.6-0.9 \mathrm{mCi} / \mathrm{mg}$ sp act. In preliminary experiments we determined that the preparations of ${ }^{125} \mathrm{I}$ vWF, both native and asialo, had a multimeric composition identical to that of the unlabeled proteins (4). The ${ }^{125}$ I-fibrinogen was $92 \%$ clottable.

Monoclonal antibodies. The anti-GPIb and the anti-GP IIb/IIIa monoclonal antibodies were a gift from Dr. Robert R. Montgomery and Dr. Thomas J. Kunicki (The Blood Center of S. E. Wisconsin, Milwaukee, WI). Both antibodies, designated AP.1 and AP.2, respectively, have been fully characterized (23). The control monoclonal antibody used (B 33.1) is an anti-HLA-D-related common determinant that does not react with platelets (24). Monoclonal IgG were prepared from ascites fluid by adsorption-elution from staphylococcal protein $\mathrm{A}$ covalently coupled to Sepharose CL-4B (Sigma Chemical Co., St. Louis, MO), according to the method of Ey et al. (25). Reduced SDSpolyacrylamide gels ( $10 \%$ acrylamide with $5 \%$ cross-linking) demonstrated that the purified fractions essentially contained only the heavy and light chains of IgG.

Preparation of washed platelet suspensions. Washed platelets for aggregation and binding studies were prepared from blood drawn into one-sixth final volume of acid/citrate/dextrose, $\mathrm{pH}$ 4.5. Platelet-rich plasma was obtained as described previously (4). For some experiments, it was labeled before washing by incubating $20 \mathrm{ml}$ with $0.5 \mu \mathrm{Ci}$ $\left[{ }^{14} \mathrm{C}\right]$ serotonin $\left(5\right.$-hydroxy $\left[2-{ }^{14} \mathrm{C}\right]$ tryptamine creatinine sulfate; Amersham Corp., Arlington Heights, IL). Platelets were washed free of plasma constituents by the albumin density-gradient technique of Walsh et al. (26), with minor modifications, consisting essentially of the addition of apyrase (grade III; Sigma Chemical Co.) to the plateletrich plasma ( $5 \mathrm{U} / \mathrm{ml}$, based on $5^{\prime}$-ATPase activity) and to the buffer used in the two subsequent washes ( 1 and $0.2 \mathrm{U} / \mathrm{ml}$, respectively). The platelets were finally resuspended in Tyrode buffer, $\mathrm{pH} 7.35$ (4). The albumin concentration in the platelet suspension was, at that point, between 29 and $42 \mathrm{mg} / \mathrm{ml}$ (range of 15 measurements) and represented carry-over from the washing procedure. All subsequent dilutions were made in Tyrode buffer, $\mathrm{pH} 7.35$, containing $20 \mathrm{mg} / \mathrm{ml}$ albumin.

Aggregation studies. The normal volunteers and patients studied gave their informed consent, according to the Declaration of Helsinki. All reported that they had taken no medications during the week before testing. The three patients with severe afibrinogenemia had unmeasurable plasma fibrinogen levels and platelet fibrinogen content of $4.4,4.5$, and $7 \mu \mathrm{g} / 10^{9}$ platelets (normal range of platelet fibrinogen concentration, $360-550 \mu \mathrm{g} / 10^{9}$ platelets), respectively. These determinations were obtained by radioimmunoassay (kindly performed by Dr. E. F. Plow, Scripps Clinic and Research Foundation, La Jolla, CA). All aggregation studies were performed in siliconized glass cuvettes placed in an aggregometer (Chrono-Log Corp., Havertown, PA) at $37^{\circ} \mathrm{C}$. The platelet suspension was constantly stirred at $1,200 \mathrm{rpm}$ using a Teflon-coated magnetic stirrer. ADP (sodium salt, grade X), ristocetin (sulfate salt, $>90 \%$ ristocetin A), and 5 -p-fluorosulfonylben- zoyladenosine (FSBA) were from Sigma Chemical Co.; $\alpha$-thrombin was a gift from Dr. J. W. Fenton II (New York State Department of Health, Albany, NY). Release of $\left[{ }^{14} \mathrm{C}\right]$ serotonin was measured as previously reported (4).

Binding experiments. The binding of ${ }^{125} \mathrm{I}$-asialo $\mathrm{VWF}$ to unstimulated platelets was measured in platelet-rich plasma using a final platelet count of between 2.5 and $3.0 \times 10^{8} / \mathrm{ml}$ and ${ }^{125} \mathrm{I}$-asialo vWF concentrations from 1.5 to $100 \mu \mathrm{g} / \mathrm{ml}$. After incubation for $30 \mathrm{~min}$ at room temperature $\left(22-25^{\circ} \mathrm{C}\right)$ without stirring, separation of platelet-bound from free ligand was achieved by centrifugation through $20 \%$ sucrose in Tyrode buffer, as previously described, followed by measurement of bound radioactivity $(4,27)$. Appropriate concentrations of monoclonal IgG against GPIb or GPIIb/IIIa, or control monoclonal IgG, were used in some experiments and incubated with the platelets for $10 \mathrm{~min}$ at room temperature before the radiolabeled ligand was added. Each anti-platelet antibody was used in excess of the concentration that gave at least $90 \%$ saturation as determined by specific binding isotherms obtained with ${ }^{125} \mathrm{I}$-labeled IgG. These values were, under the conditions used, $30 \mu \mathrm{g} / \mathrm{ml}$ for AP. 1 and $90 \mu \mathrm{g} / \mathrm{ml}$ for AP.2. In some experiments, ${ }^{125}$ I-native vWF was used instead of asialo vWF.

The binding of ${ }^{125}$ I-fibrinogen to washed platelets in the presence of asialo vWF was measured as follows. Washed platelets $\left(2-4 \times 10^{8}\right)$ $\mathrm{ml}$ ) were mixed with asialo vWF and calcium chloride (1-2 mM final concentration) and stirred in the aggregometer cuvette at $1,200 \mathrm{rpm}$ for $5 \mathrm{~min}$ at $37^{\circ} \mathrm{C}$. In some experiments, this incubation was done at room temperature and without stirring, but the results observed were similar. The mixture was then removed from the aggregometer, and appropriate aliquots were mixed with ${ }^{125}$-fibrinogen either in the presence or absence of excess unlabeled fibrinogen. The platelet count at that point was $1-2 \times 10^{8} / \mathrm{ml}$. After incubation at room temperature without stirring for $30 \mathrm{~min}$ or a variable period of time in time course experiments, phase separation was achieved as described above. In some experiments, monoclonal anti-GPIb IgG or anti-GPIIb/IIIa IgG, or ADP scavangers were added to the platelets together with the asialo vWF. The binding of ${ }^{125}$ I-fibrinogen induced by ADP $(20 \mu \mathrm{M})$ was measured by adding the ADP to the platelet mixture containing calcium and the ligand, without stirring. For the measurement of thrombin-induced binding, platelets at the concentration of $2.5 \times 10^{8} /$ $\mathrm{ml}$ were stimulated with $0.5 \mathrm{NIH} \mathrm{U} / \mathrm{ml}$ of $\alpha$-thrombin for $10 \mathrm{~min}$ at room temperature without stirring. Hirudin (Sigma Chemical Co.) was then added at a 16-fold excess over thrombin. After $5 \mathrm{~min}$, ${ }^{125} \mathrm{I}$ fibrinogen was added for $30 \mathrm{~min}$, and binding was measured as described above.

Binding isotherms were fitted to the experimental data, each one being the mean of duplicate or triplicate readings that agreed within $20 \%$, using least squares regression analysis. Proportionate standard error weighting (28) was used to analyze double-reciprocal plots.

\section{Results}

Platelet aggregation induced by asialo vWF. Suspensions of normal washed platelets stirred in the aggregometer failed to show detectable aggregation upon addition of asialo vWF (Fig. 1). Subsequent addition of either calcium chloride or fibrinogen also failed to produce any response. When both calcium and fibrinogen were added to the mixture of platelets and asialo vWF, however, prompt aggregation was observed (Fig. 1). Fibrinogen and calcium, in the absence of asialo vWF, had no effect (Fig. 1). Aggregation of washed platelets in the presence of asialo vWF, fibrinogen, and calcium, was completely blocked by both the monoclonal antibody against GPIb and the one against GPIIb/IIIa (Fig. 2). Similar results were observed in platelet-rich plasma. Aggregation was also blocked by apyrase, at a concentration of $5 \mathrm{U} / \mathrm{ml}$ based on $5^{\prime}$-ATPase activity (Fig. $2)$, and by FSBA at $1 \times 10^{-4} \mathrm{M}$.

Fibrinogen was a necessary cofactor for platelet aggregation 


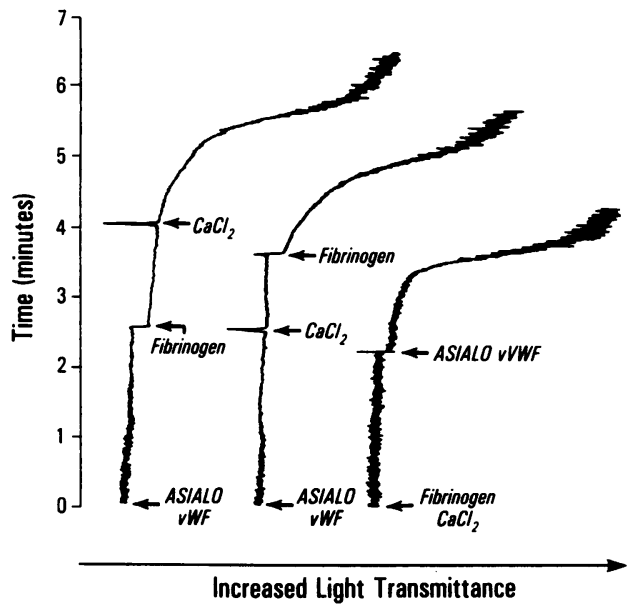

Figure 1. Aggregation of normal washed platelets induced by asialo vWF. Washed platelets, prepared as described in the Methods section, were added into the aggregometer cuvette $(0.336 \mathrm{ml}$ with 2.38 $\times 10^{8}$ platelet $\left./ \mathrm{ml}\right)$ and mixed with either $20 \mu \mathrm{l}$ of asialo vWF (0.82 $\mathrm{mg} / \mathrm{ml})$ or $40 \mu \mathrm{l}$ of fibrinogen $(20 \mathrm{mg} / \mathrm{ml})$ plus $4 \mu \mathrm{l}$ of calcium chloride $(0.1 \mathrm{M})$, as indicated. After the mixture was stirred in the aggregometer and lack of aggregation was observed, fibrinogen ( $40 \mu \mathrm{l})$ was added to one of the mixtures containing asialo vWF (left trace), and calcium chloride $(4 \mu \mathrm{l})$ was added to the other (middle trace). Asialo vWF $(20 \mu \mathrm{l})$ was added to the mixture containing fibrinogen and calcium chloride (right trace). Aggregation was observed, at this point, in the latter mixture, but not in the others. Aggregation was prompt, however, when calcium chloride $(4 \mu \mathrm{l})$ was added to the mixture already containing fibrinogen (left trace), or fibrinogen (40 $\mu l)$ was added to the mixture already containing calcium chloride (middle trace). The final concentrations in each mixture were as follows: asialo vWF, $41 \mu \mathrm{g} / \mathrm{ml}$; fibrinogen, $2 \mathrm{mg} / \mathrm{ml}$; calcium chloride, $1 \mathrm{mM}$.

induced by asialo vWF and acted in a dose-dependent manner. When a constant concentration of asialo vWF was maintained, increasing the concentration of fibrinogen resulted in a more prompt and pronounced aggregation (Fig. 3). Conversely, when fibrinogen was present at concentrations that were maximally effective, the onset and extent of aggregation were dependent on the amount of asialo vWF added to the mixture (Fig. 3). In accordance with the results observed with washed normal platelets, the response of afibrinogenemic platelet-rich plasma to asialo vWF was markedly impaired, but it was restored to normal by the addition of fibrinogen. Similar results have been previously reported (12).

Release of $\left[{ }^{14} \mathrm{C}\right]$ serotonin was observed when asialo vWF was stirred with washed platelets in the absence of fibrinogen and calcium, and, therefore, in the absence of macroscopic aggregation. The release was related to the amount of asialo vWF added to the mixture and was always consistently greater than in control experiments where platelets were mixed with native vWF or fibrinogen alone. Release was more pronounced when aggregation occurred in the presence of asialo vWF, calcium, and fibrinogen (Table I).

Binding of ${ }^{125} I$-asialo $v W F$ to unstimulated platelets. ${ }^{125} \mathrm{I}-$ asialo vWF bound in a saturable manner to unstimulated platelets in platelet-rich plasma, without stirring (Fig. 4). In five separate experiments it was determined that total binding at saturation was $0.59 \pm 0.21$ (SD) $\mu \mathrm{g} / 10^{8}$ platelets, with an apparent dissociation constant $\left(K_{d}\right)$ of $28 \pm 4.3 \mu \mathrm{g} / \mathrm{ml}$. The

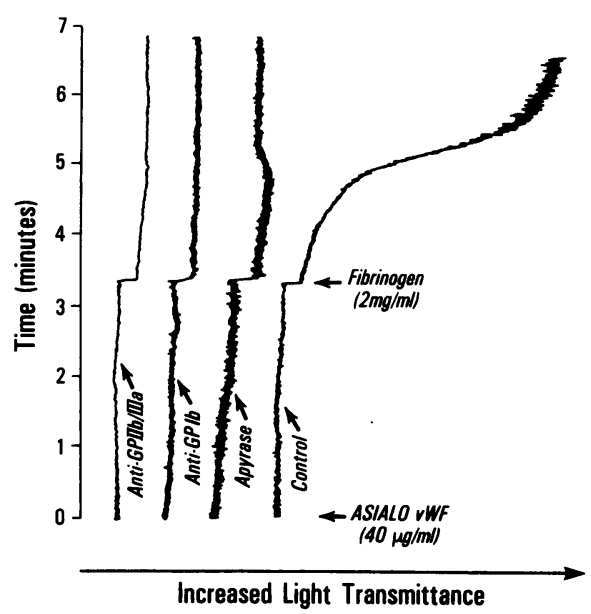

Figure 2. Aggregation of normal washed platelets induced by asialo vWF. Washed platelets $\left(0.316 \mathrm{ml}\right.$ with $2.53 \times 10^{8}$ platelet $\left./ \mathrm{ml}\right)$ were mixed with $20 \mu \mathrm{l}$ of asialo vWF $(0.82 \mathrm{mg} / \mathrm{ml}), 4 \mu \mathrm{l}$ of $\mathrm{CaCl}_{2}(0.1 \mathrm{M})$, and $20 \mu \mathrm{l}$ of one of the following reagents, as indicated: $0.02 \mathrm{M}$ Tris, $0.15 \mathrm{M} \mathrm{NaCl}$ buffer, $\mathrm{pH} 7.3$ (control trace); anti-GPIb $(0.6 \mathrm{mg} / \mathrm{ml}$ ) or anti-GPIIb/IIIa monoclonal IgG $(1.8 \mathrm{mg} / \mathrm{ml})$; or apyrase $(100$ $\mathrm{U} / \mathrm{ml}$, based on 5'-ATPase activity). After the mixture was stirred in the aggregometer and lack of aggregation was observed, $40 \mu \mathrm{l}$ of fibrinogen $(20 \mathrm{mg} / \mathrm{ml})$ was added to all mixtures. Aggregation was observed only in the control mixture.

anti-GPIb antibody inhibited the binding $>75 \%$, whereas the anti-GP IIb/IIIa antibody had only a minimal effect (Fig. 4). The binding of ${ }^{125} \mathrm{I}$-native vWF to unstimulated platelets was similar to that of ${ }^{125} \mathrm{I}$-asialo $\mathrm{vWF}$ in the presence of the antiGPIb antibody (Fig. 4). In these two cases the binding was not saturable. Neither apyrase nor FSBA, at concentrations that inhibited fibrinogen binding (see below), had any effect on the binding of asialo vWF to unstimulated platelets.

Binding of ${ }^{125}$ I-fibrinogen to platelets in the presence of asialo $v W F$. Asialo vWF induced the time-dependent binding

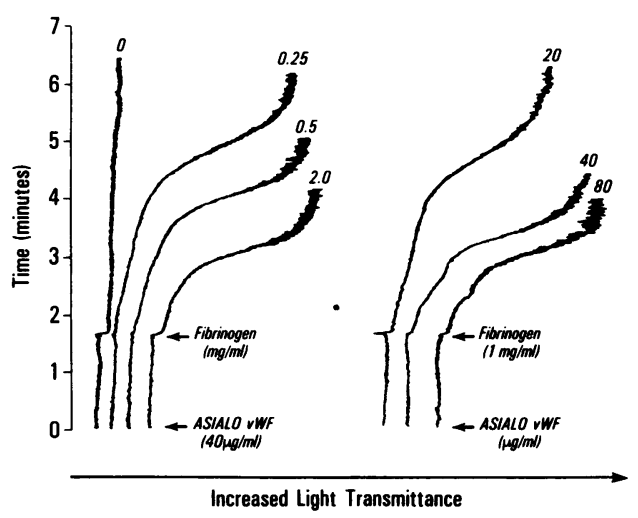

Figure 3. Effect of asialo vWF and fibrinogen concentrations on aggregation of washed platelets. Washed platelets $(0.316 \mathrm{ml}$ with 2.53 $\times 10^{8}$ platelet $/ \mathrm{ml}$ ) were mixed with $4 \mu \mathrm{l}$ of calcium chloride $(0.1 \mathrm{M})$ and $40 \mu \mathrm{l}$ of asialo vWF to give either a final concentration of 40 $\mu \mathrm{g} / \mathrm{ml}$ for the four traces on the left, or the concentration indicated for each one of the traces on the right. After the mixture was stirred in the aggregometer to set a baseline, $40 \mu$ l of fibrinogen, or $0.02 \mathrm{M}$ Tris, $0.15 \mathrm{M} \mathrm{NaCl}, \mathrm{pH} 7.3$, was added to each mixture to achieve either the final concentration indicated for each trace on the left, or a concentration of $1 \mathrm{mg} / \mathrm{ml}$ for the three traces on the right. Changes in light transmittance were then recorded. 
Table I. Release of $\left[{ }^{14} \mathrm{C}\right]$ Serotonin Induced by Asialo $v W F$

\begin{tabular}{llcl}
\hline Agonist & & Release & Aggregation \\
\hline \multirow{3}{*}{ Asialo vWF } & $(20 \mu \mathrm{g} / \mathrm{ml})$ & $9.9-13.3^{*}$ & - \\
& $(40 \mu \mathrm{g} / \mathrm{ml})$ & $14-27^{*}$ & - \\
& $(60 \mu \mathrm{g} / \mathrm{ml})$ & $15.7-33^{*}$ & - \\
Native vWF & $(60 \mu \mathrm{g} / \mathrm{ml})$ & 4.3 & - \\
& $(240 \mu \mathrm{g} / \mathrm{ml})$ & 7.9 & - \\
Asialo vWF & $(60 \mu \mathrm{g} / \mathrm{ml})$ & 50.3 & + \\
$\begin{array}{c}\text { (Fibrinogen } \\
+ \text { CaCl })\end{array}$ & & & - \\
Fibrinogen $+\mathrm{CaCl}_{2}$ & 5.1 & \\
\hline
\end{tabular}

The mixture of washed platelets (final count $2 \times 10^{8} / \mathrm{ml}$ ) and $\mathrm{vWF}$, at the final concentrations indicated, was stirred $(1,200 \mathrm{rpm})$ in the aggregometer at $37^{\circ} \mathrm{C}$ for $5 \mathrm{~min}$. Imipramine was present at $5 \mu \mathrm{M}$ to block any reuptake of serotonin. When fibrinogen and $\mathrm{CaCl}_{2}$ were present, they were at $1 \mathrm{mg} / \mathrm{ml}$ and $2 \mathrm{mM}$, respectively. The mixture was then rapidly transferred into a microcentrifuge tube and the platelets sedimented for $4 \mathrm{~min}$ at $13,000 \mathrm{~g}$. The radioactivity in $5 \mu \mathrm{l}$ of the supernatant obtained after spinning out the platelets was counted in a liquid scintillation spectrometer and expressed as percentage of releasable serotonin. The latter was determined by adding to the platelets $\alpha$-thrombin at a final concentration of $1 \mathrm{NIH} \mathrm{U/ml}$. Releasable serotonin accounted for $>80 \%$ of the total content in lysed platelets. Aggregation, as indicated in the last column, was monitored in the aggregometer.

* Starred results represent the range of three experiments. All other results represent single experiments.

of ${ }^{125}$ I-fibrinogen to washed platelets, and equilibrium was reached in $20 \mathrm{~min}$ at room temperature. The binding of ${ }^{125} \mathrm{I}-$ fibrinogen was maximal at concentrations of asialo vWF between 20 and $40 \mu \mathrm{g} / \mathrm{ml}$, but then decreased as the concentration of asialo vWF was increased (Fig. 5). The binding of

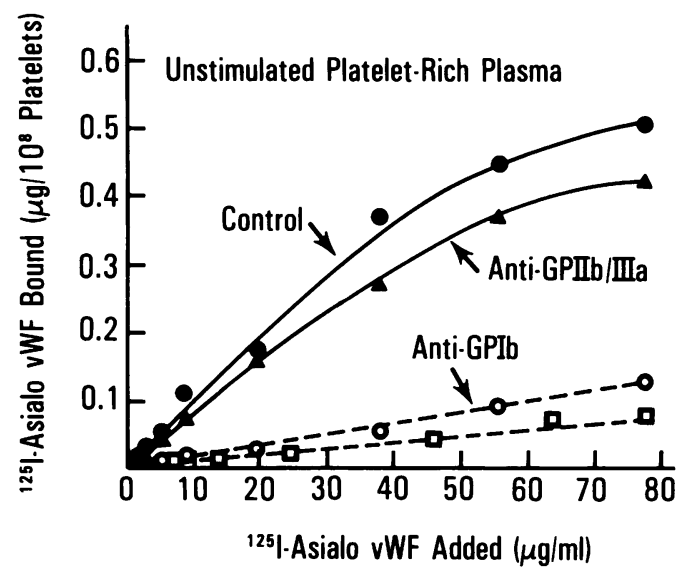

Figure 4. Binding of ${ }^{125} \mathrm{I}$-asialo vWF to unstimulated platelets. Platelet-rich plasma $\left(70 \mu \mathrm{l}\right.$; final concentration $3 \times 10^{8}$ platelet $\left./ \mathrm{ml}\right)$ was mixed with $30 \mu \mathrm{l}$ of $0.02 \mathrm{M}$ Tris, $0.15 \mathrm{M} \mathrm{NaCl}, \mathrm{pH} 7.3$ (॰, control), anti-GPIb IgG (0), or anti-GPIIb/IIIa IgG ( $₫$; final concentration 30 $\mu \mathrm{g} / \mathrm{ml}$ and $90 \mu \mathrm{g} / \mathrm{ml}$, respectively), for $10 \mathrm{~min}$ at $22-25^{\circ} \mathrm{C}$ without agitation. ${ }^{125} \mathrm{I}$-Asialo vWF $(25 \mu \mathrm{l})$ was then added in final concentrations from 1.6 to $78 \mu \mathrm{g} / \mathrm{ml}$ and incubated for $30 \mathrm{~min}$ under the same conditions. Binding was measured as described in the text. Open squares indicate the curve obtained in a control experiment in which platelets were incubated with ${ }^{125}$ I-native vWF.

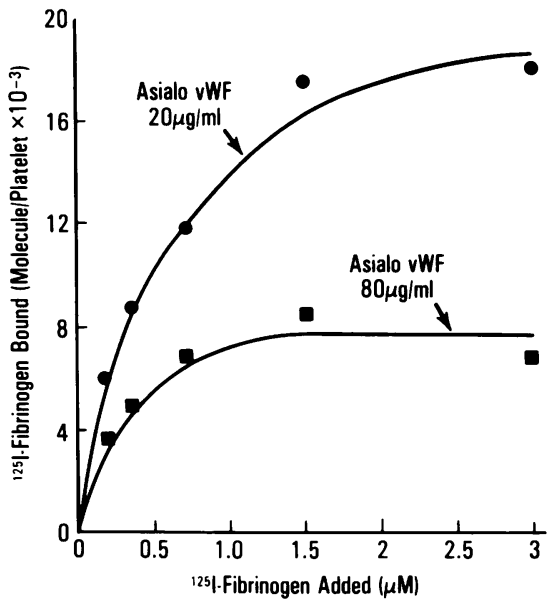

Figure 5. Effect of asialo vWF concentration on the binding of ${ }^{125} \mathrm{I}$ fibrinogen to platelets. Washed platelets $\left(0.356 \mathrm{ml}\right.$ with $3.37 \times 10^{8}$ platelet $/ \mathrm{ml}$ ) were mixed in the aggregometer cuvette with $4 \mu \mathrm{l}$ of calcium chloride $(0.1 \mathrm{M})$ and $40 \mu \mathrm{l}$ of asialo vWF to give a final concentration of $20 \mu \mathrm{g} / \mathrm{ml}(\bullet)$ or $80 \mu \mathrm{g} / \mathrm{ml}(\bullet)$, as indicated. The mixture was stirred at $37^{\circ} \mathrm{C}$ for $5 \mathrm{~min}$, while changes in light transmission were recorded to ensure that no macroscopic aggregation was occurring. The mixture was then divided into $40-\mu$ l aliquots, and $25 \mu \mathrm{l}$ of ${ }^{125} \mathrm{I}$-fibrinogen was added to give the final concentrations indicated. This was immediately followed by $55 \mu 1$ of either $0.02 \mathrm{M}$ Tris, $0.15 \mathrm{M} \mathrm{NaCl}$, pH 7.3, to measure total binding, or a 20-fold excess of unlabeled fibrinogen to measure nonspecific binding. The incubation was continued for $30 \mathrm{~min}$ at $22-25^{\circ} \mathrm{C}$ without stirring, and platelet-bound radioactivity was then measured as described in the Methods section. Results shown represent specific binding.

${ }^{125}$ I-fibrinogen induced by asialo vWF was saturable, and it was inhibited $>75 \%$ by excess unlabeled fibrinogen (Fig. 6 ). It required 1-2 $\mathrm{mM} \mathrm{Ca}^{2+}$ and was completely blocked by $2 \mathrm{mM}$ EDTA. In 11 separate experiments, performed with platelets

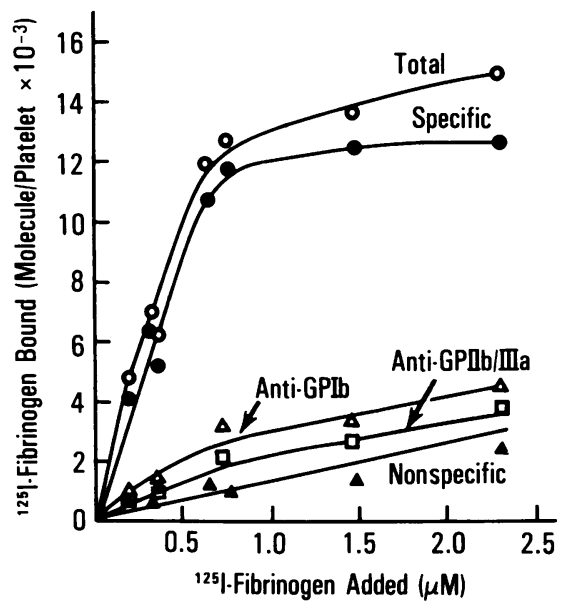

Figure 6. Saturation binding of ${ }^{125}$ I-fibrinogen induced by asialo vWF. This experiment was performed essentially as described in the legend to Fig. 5, except that platelets and asialo vWF were incubated at $22-25^{\circ} \mathrm{C}$ without stirring. The mixtures also contained monoclonal anti-GPIb IgG $(\Delta ; 30 \mu \mathrm{g} / \mathrm{ml})$, or anti-GPIIb/IIIa IgG ( $\square ; 90$ $\mu \mathrm{g} / \mathrm{ml}$ ), as indicated, or $0.02 \mathrm{M}$ Tris, $0.15 \mathrm{M} \mathrm{NaCl}$, pH 7.3 (curves

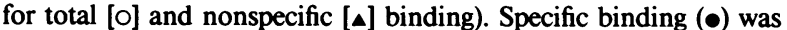
calculated by subtracting nonspecific (determined in the presence of a 20 -fold excess of unlabeled fibrinogen) from total binding. The binding measured in the presence of the monoclonal antibodies is reported as total binding. 
from different donors, specific binding at saturation was between 3.2 and $27.7 \times 10^{3}$ molecule/platelet, with an apparent $K_{\mathrm{d}}$ between 0.28 and $1.18 \times 10^{-6} \mathrm{M}$. The binding of ${ }^{125} \mathrm{I}$-fibrinogen induced by asialo vWF was markedly reduced by the antiGPIb monoclonal antibody (Fig. 6). This antibody had no effect on the binding of fibrinogen induced by thrombin or ADP (4). In addition, the anti-GPIIb/IIIa antibody inhibited the binding of ${ }^{125}$ I-fibrinogen induced by asialo vWF (Fig. 6), but in this case, the inhibition was similar to that observed when ADP or thrombin were used as agonists. Apyrase (5 $\mathrm{U} / \mathrm{ml})$ and FSBA $\left(1 \times 10^{-4} \mathrm{M}\right)$, at concentrations that blocked the thrombin-induced binding of fibrinogen, also inhibited the binding induced by asialo vWF.

\section{Discussion}

This study shows that asialo vWF induces platelet aggregation by interacting with the membrane GPIb, followed by release of dense granule content and fibrinogen binding to sites exposed on the GPIIb/IIIa complex. These latter receptors are identical, or closely related, to those involved in platelet aggregation induced by agonists like ADP and thrombin $(4,9$, $10)$, as shown by blocking obtained with the same monoclonal antibody $(4,23)$. As with other platelet agonists $(2,6-8)$, endogenous ADP is essential for fibrinogen binding induced by asialo vWF. This was demonstrated by the inhibitory effect of apyrase, which degrades ADP to AMP, and FSBA, a competitive receptor antagonist of ADP.

Previous studies using Bernard-Soulier platelets had suggested the possibility that asialo vWF interacts with GPIb (13). Further evidence in favor of this hypothesis is provided here by the experiments performed with the anti-GPIb antibody, which blocked asialo vWF binding. Since the same antibody also blocks ristocetin-induced binding of native vWF (4), both ligands must interact with the same or closely related epitopes on GPIb. Moreover, the vWF binding sites appear to be expressed on unstimulated platelets. The direct interaction of asialo vWF with GPIb is probably related to asialo vWF's decreased negative charge as compared with the native molecule (29). Such a concept is in agreement with the proposed mechanism of action of the electropositive ristocetin molecule in promoting vWF binding to platelets (30).

Asialo vWF induces ADP-mediated fibrinogen binding to platelets with an apparent $K_{\mathrm{d}}$ similar to that measured with other agonists $(2,5-8)$. Competition existed, however, between the two ligands for binding to GPIIb/IIIa, as suggested by the fact that less fibrinogen bound to platelets when higher concentrations of asialo vWF were present. Such a finding is in agreement with direct competition binding studies performed with native vWF (31), as well as with asialo vWF (De Marco, L., R. Bader, S. Russell, and Z. M. Ruggeri, unpublished observation). These results are not likely to be due to increased release of platelet fibrinogen induced by the higher concentrations of asialo vWF. In fact, it has been shown that the binding of exogenous fibrinogen (32), as well as of vWF (27), to ADPor thrombin-stimulated platelets is the same in normal and afibrinogenemic individuals, suggesting that released platelet fibrinogen has little influence on it. This is possibly due to the fact that additional GPIIb/IIIa molecules, contained in the membrane of $\alpha$-granules, may be involved in interacting with intracellular ligands when they emerge on the platelet surface in a process of membrane fusion (33).
Our results indicate that platelet aggregation induced by asialo vWF required exogenous fibrinogen and was correlated to the amount of asialo vWF present, even though the latter competed with fibrinogen for binding to GPIIb/IIIa. In agreement with previously reported results (34), we found that aggregation occurred at concentrations of asialo vWF that caused occupancy of only a small fraction of the total available sites on GPIb. The fact that more asialo vWF was required to stimulate washed platelets than platelet-rich plasma (13) may reflect functional damage incurred during the isolation procedure. Altogether, these findings suggest that vWF and fibrinogen cooperate in promoting aggregation.

Asialo vWF is not known to occur in vivo, although its local generation at sites of vascular injury has been postulated (13). There is evidence, however, that platelet aggregation after the ristocetin-induced binding of native vWF to GPIb requires, as in the case of asialo vWF, availability of divalent cations and secretion of dense granule content (35). Moreover, integrity of the GPIIb/IIIa complex is also necessary (36). These events are difficult to appreciate, as they are masked by the concurrent ristocetin-induced agglutination of platelets that is independent of active platelet metabolism (37). Based on these observations, and on the mechanisms here described, we propose that the interaction of either native or asialo vWF with GPIb not only promotes the initial attachment of platelets to the subendothelium, but also plays a role in subsequent events leading to the formation of platelet thrombi at sites of vascular injury.

\section{Acknowledgments}

We wish to thank Drs. Robert R. Montgomery, Thomas J. Kunicki, Bice Perussia, Giorgio Trinchieri, and John W. Fenton II for providing important reagents; Dr. Theodore S. Zimmerman for helpful advice; and Claire Jackson for excellent secretarial support. Dr. Augusto B. Federici helped with the preparation of purified native and asialo vWF.

This work was supported in part by grant "Progetto Finalizzato Ingegneria Genetica Sottoprogetto Basi Molecolari Delle Malattie Ereditarie" of the Consiglio Nazionale delle Ricerche, Rome, Italy; grant RG 473.84 from the North Atlantic Treaty Organization; and grant HL 31950 from the National Institutes of Health.

\section{References}

1. Weiss, H. J., H. R. Baumgartner, T. B. Tschopp, V. T. Turitto, and D. Cohen. 1978. Correction of factor VIII of the impaired platelet adhesion to subendothelium in von Willebrand's disease. Blood. 51: 267-279.

2. Marguerie, G. A., E. F. Plow, and T. S. Edgington. 1979. Human platelets possess an inducible and saturable receptor specific for fibrinogen. J. Biol. Chem. 254:5357-5363.

3. Kao, K.-J., S. V. Pizzo, and P. A. McKee. 1979. Demonstration and characterization of specific binding sites for factor VIII/von Willebrand factor on human platelets. J. Clin. Invest. 63:656-664.

4. Ruggeri, Z. M., L. De Marco, L. Gatti, R. Bader, and R. R. Montgomery. 1983. Platelets have more than one binding site for von Willebrand factor. J. Clin. Invest. 72:1-12.

5. Bennett, J. S., and G. Vilaire. 1979. Exposure of platelet fibrinogen receptors by ADP and epinephrine. J. Clin. Invest. 64: 1393-1401.

6. Plow, E. F., and G. A. Marguerie. 1980. Induction of the fibrinogen receptor on human platelets by epinephrine and the combination of epinephrine and ADP. J. Biol. Chem. 255:10971-10977.

7. Plow, E. F., and G. A. Marguerie. 1980. Participation of ADP in the binding of fibrinogen to thrombin-stimulated platelets. Blood $56: 553-555$. 
8. Hawiger, J., S. Parkinson, and S. Timmons. 1980. Prostacyclin inhibits mobilisation of fibrinogen-binding sites on human ADP- and thrombin-treated platelets. Nature (Lond.). 283:195-197.

9. Coller, B. S., E. I. Peerschke, L. E. Scudder, and C. A. Sullivan. 1983. A murine monoclonal' antibody that completely blocks the binding of fibrinogen to platelets produces a thrombasthenic-like state in normal platelets and binds to glycoproteins IIb and/or IIIa. J. Clin. Invest. 72:325-338.

10. Bennett, J. S., J. A. Hoxie, S. F. Leitman, G. Vilaire, and D. B. Cines. 1983. Inhibition of fibrinogen binding to stimulated human platelets by a monoclonal antibody. Proc. Natl. Acad. Sci. USA. 80:2417-2421.

11. Vermylen, J., G. De Gaetano, M. B. Donati, and M. Verstraete. 1974. Platelet-aggregating activity in neuraminidase-treated human cryoprecipitates: its correlation with factor-VIII-related antigen. $B r . J$. Haematol. 26:645-650.

12. Vermylen, J., D. Bottecchia, and H. Szpilman. 1976. Factor VIII and human platelet aggregation. III. Further studies on aggregation of human platelets by neuraminidase-treated human factor VIII. Br. J. Haematol. 34:321-330.

13. De Marco, L., and S. S. Shapiro. 1981. Properties of human asialo-factor VIII. A ristocetin-independent platelet-aggregating agent. J. Clin. Invest. 68:321-328.

14. Newman, J., A. J. Johnson, M. H. Karpatkin, and S. Puszkin. 1971. Methods for the production of clinically effective intermediateand high-purity factor VIII concentrates. Br. J. Haematol. 21:1-20.

15. Switzer, M. E., and P. A. McKee. 1976. Studies on human antihemophilic factor. Evidence for a covalently linked subunit structure. J. Clin. Invest. 57:925-937.

16. Ruggeri, Z. M., P. M. Mannucci, R. Bader, and T. Barbui. 1978. Factor VIII related properties in platelets from patients with von Willebrand's disease. J. Lab. Clin. Med. 91:132-140.

17. Ruggeri, Z. M., and T. S. Zimmerman. 1981. The complex multimeric composition of Factor VIII/von Willebrand factor. Blood. 57:1140-1143.

18. Kazal, L. A., S. Amsel, O. P. Miller, and L. M. Tocantins. 1963. The preparation and some properties of fibrinogen precipitated from human plasma by glycine. Proc. Soc. Exp. Biol. Med. 113:989994.

19. Laemmli, U. K. 1970. Cleavage of structural proteins during the assembly of the head of bacteriophage T4. Nature (Lond.). 227: 680-685.

20. Federici, A. B., J. H. Elder, L. De Marco, Z. M. Ruggeri, and T. S. Zimmerman. 1984. Carbohydrate moiety of von Willebrand factor is not necessary for maintaining multimeric structure and ristocetin cofactor activity but protects from proteolytic degradation. J. Clin. Invest. 74:2049-2055.

21. Warren, L. 1959. The thiobarbituric acid assay of sialic acids. J. Biol. Chem. 234:1971-1975.

22. Fraker, D. J., and J. C. Speck. 1978. Protein and cell membrane iodinations with a sparingly soluble chloroamide, 1,3,4,6-tetrachloro- 3a,6a-diphenylglycoluril. Biochem. Biophys. Res. Commun. 80:849857.

23. Montgomery, R. R., T. J. Kunicki, C. Taves, D. Pidard, and M. Corcoran. 1983. Diagnosis of Bernard-Soulier syndrome and Glanzmann's thrombasthenia with a monoclonal assay on whole blood. $J$. Clin. Invest. 71:385-389.

24. Perussia, B., G. Trinchieri, D. Lebman, J. Jankiewicz, B. Lange, and G. Rovera. 1982. Monoclonal antibodies that detect differentiation surface antigens on human myelomonocytic cells. Blood. 59:382-392.

25. Ey, P. L., S. J. Prowse, and C. R. Jenkin. 1978. Isolation of pure IgG1, IgG2, and IgG2b immunoglobulins from mouse serum using protein A-Sepharose. Immunochemistry. 15:429-436.

26. Walsh, P. N., D. C. B. Mills, and J. G. White. 1977. Metabolism and function of human platelets washed by albumin density gradient separation. Br. J. Haematol. 36:281-296.

27. Ruggeri, Z. M., R. Bader, and L. De Marco. 1982. Glanzmann thrombasthenia: deficient binding of von Willebrand factor to thrombinstimulated platelets. Proc. Natl. Acad. Sci. USA. 79:6038-6041.

28. Cleland, W. W. 1979. Statistical analysis of enzyme kinetic data. Methods Enzymol. 63:103-138.

29. Fulcher, C. A., Z. M. Ruggeri, and T. S. Zimmerman. 1983. Isoelectric focusing of human von Willebrand factor in urea-agarose gels. Blood. 61:304-310.

30. Coller, B. S., and H. R. Gralnick. 1977. Studies on the mechanism of ristocetin-induced platelet agglutination. Effects of structural modification of ristocetin and vancomycin. J. Clin. Invest. 60: 302-312.

31. Timmons, S., M. Kloczewiak, and J. Hawiger. 1984. ADPdependent common receptor mechanism for binding of von Willebrand factor and fibrinogen to human platelets. Proc. Natl. Acad. Sci. USA. 81:4935-4939.

32. Marguerie, G. A., N. Thomas-Maison, M. J. Larrieu, and E. F. Plow. 1982. The interaction of fibrinogen with human platelets in a plasma milieu. Blood. 59:91-95.

33. Keller, D. M., M. H. Ginsberg, E. F. Plow, and V. L. Woods. 1984. Thrombin can induce cell surface display of a pool of platelet glycoprotein IIb and IIIa heterodimer distinct from that on the surface of resting platelets. Blood. 64(Suppl. 1):248a.

34. Catalano, P. M., S. S. Shapiro, L. De Marco, and F. London. 1981. Binding properties of tritiated human asialo-factor VIII (ASVIII) to human platelets. Blood. 58(Suppl. 1):190a.

35. Weiss, H. J., J. Rogers, and H. Brand. 1973. Defective ristocetin-induced platelet aggregation in von Willebrand's disease and its correction by factor VIII. J. Clin. Invest. 52:2697-2707.

36. Chediak, J., M. C. Telfer, B. VanderLaan, B. Maxey, and I. Cohen. 1979. Cycles of agglutination-disagglutination induced by ristocetin in thrombasthenic platelets. Br. J. Haematol. 43:113-126.

37. Allain, J. P., H. A. Cooper, R. H. Wagner, and K. M. Brinkhous. 1975. Platelets fixed with paraformaldehyde: a new reagent for assay of von Willebrand factor and platelet aggregating factor. $J$. Lab. Clin. Med. 85:318-328. 